siological essays), the scientific assistant, as we shall call him, whose office was but recently, after a tenure of some years, vacated by the eminent pathological anatomist, Professor Schweigger, gives three different courses of instruction-one on ophthalmoscopy, another on the diseases of refraction and accommodation, and a third on the pathological anatomy of the eye. Professor von Graefe himself discourses on the diseases of the eye, as we have stated, three times a week, from ten to eleven o'clock in the morning. There were, on an average, from fifty to sixty hearers attending-among them always a number of qualified medical men. They are seated on chairs in two double rows, confronting each other, and leaving a passage between them for the patients presented, and particularly for the lecturer, who seldom occupies a seat, and ever and anon repairs to the black board, which, though moveable, rivals indeed the most stable of fixtures : it is his most cherished instrument of instruction, in the nse of which, whether lecturing, or conversing, or pausing from an operation, he is untiring, and the convenience of which he is very apt to suggest to any party conveying or seeking some information. The cases to be produced are, on the day preceding a lecture, selected by Von Graefe himself, or more frequently, under his direction, summoned by the junior clinieal assistant; who also, seconded by one of the male attendants, controls their movements to and from the lecture-room. A few minutes before the commencement of his lecture the professor spends in glancing at some of the cases in the anteroom. Some four or five of those among the students who believe themselves to be sufficiently advanced not to be listeners only, examine the cases previously to the lecture, in order to prepare themselves for the impending interrogatory. The lecturer does not profess within a given period to exhaust the whole subject of ophthalmology; his lectures are clinical in the received sense of the term. As cases emerge, or a series of cases, invested with practical interest, they are made the substratum of instruction. There is, however, scarcely anything of importance missed during the term; and whatever is taken up is certain to be exhaustively treated. The number of cases dwelt on in this manner are from two to five in the course of a lecture, towards the end of which as many or more are cursorily dealt with. Not unfrequently, the suggestion or request of a friend is sufficient for a subject to be made the item of discourse. The delivery of the lecturer is spirited in the highest degree, signalised by the most perfect ease and freedom, sometimes perhaps too rapid, though ever elevated in style. The tone is very frequently colloquial, and only becomes more measured when the teacher rises as it were with his subject-e.g., when he comes to treat on such chapters as paralytic disease, or the disorders of accommodation and refraction, or, especially, muscular asthenopia. We shall long harbour the impression we received when, having descanted in the most perspicuous strain on the last named very intricate and most interesting subject, he wound up his remarks by reminding us that the subject was one of the highest practical importance, and that the fathoming of it did honour to the human understanding. To my mind, this succinct peroration, most objectively pronounced as it was, enbodied the text of a panegyric such as in our day but few men might more rightfully claim than the speaker. We should, however, find it difficult to decide where his teaching was more instructive and suggestive; whether when he spoke on amblyopia, or when on the consistency of cataract, or, again, on the various forms of conjunctivitis and keratitis. We have once more been in the position lately of listening to teachers of great and deserved renown; but, thankful as we feel for many a valuable lesson, we did not fall in with any one who "had the elements so mixed in him".

[To be continued.]

Errata. The following corrections are required in that part of Dr. Samelson's paper which appeared in the Journal of March 24th.

Page 306, col. Ir, line 28 from bottom, for " 10.20 ", read " $10.30 "$ ".

Page 306, col. Ir, line 8 from bottom, omit "many".

Page 308, col. II, line 15 from bottom, for "mentioned above", read "here mentioned".

Page 309, col. I, line 6 from bottom, for "invariably", read "invincibly".

\section{ON THE TREATMENT OF STRABISMUS} WITHOUT OPERATION.

By C. Houthousr, Esq., Surgeon to the Westminster Hospital, and to the Surrey Ophthalmic

Hospital, etc.

[Continued from page 252.]

Case Iv. Double Convergent Strabismus of the Left. Eyje to one Line, of the Right to three and a half Lines, from Paralysis of the Left External Rectus Muscle. Mary D., aged 52, married, came under my care at the Surrey Ophthalmic Hospital on August 17th, 1865, for double convergent strabismus, which had made its appearance eight days previously, having been preceded by what seems to have been a slight conjunctivitis in consequence of cold; the eye being "bloodshot", slightly watery, and affected with "a pricking sensation", and the lids "gummy" in the morning. Two days after this inflammation had subsided, the patient was seized suddenly, in the middle of the day, with a severe shooting pain in the left eyeball, extending over the left side of the forehead and head and the upper part of the nose on the same side, together with much giddiness, confusion of vision, and diplopia, so that she had been afraid to trust herself to go about alone ever since.

Condition on Application. The above symptoms were still present with scarcely diminished severity. The eyeball was very tender on pressure, and its movements were painful ; but its tension was normal, and there was no vascularity of the sclerotic or conjunctiva. The pain over the forehead and head followed exactly the course of the supraorbital and supratrochlear nerves, pressure on which, at their points of exit from the orbit, caused much suffering. On examining the movements of the eje, the right being covered, they were found to be limited in the outward directions; $i$. e., the cornea could be brought exactly to a central position between the canthi, but not beyond; and the diagonal movements in an outward direction were defective. On the patient trying to look outwards, no action of the oblique muscles could be detected. The power of inverting the eye was perfect. On attempting to grasp a pen held a little to her left, she always clutched at it as if it were still more to her left than it really was. The pupil was of normal size, and responded readily to the stimulus of light. The eye was presbyopic to $\frac{1}{14}$; otherwise its vision was good-indeed, rather better than that of the right eye; for, whereas the latter had an acuity of vision of only $\frac{2}{3}$, the left was normal. The vision of the right eye was $\frac{20}{30}$, and with 30 lens, $\frac{20}{2}$, and that of the left eye $\frac{20}{20}$; so that the defect of sight of the right eye was due to hypermetropia. On closing the paralysed eye, the movements of the right eye and of its pupil were found to be perfect. 
When looking at my finger, placed three feet in front of her face, with the good eye, the left being shaded, the latter was never inverted; but, on regarding the finger with the left eye while the right was covered, the latter was fully inverted to at least four lines or more. The most striking features of this case, however, were manifested when both the eyes were uncovered. Evidently all the volition of the patient was exerted and directed towards the paralysed muscle, in order to prevent its antagonist from drawing that eye inwards ; and this effort was made manifest chiefly in the sound eye, which was inverted to three and a half lines; while the paralysed eye was either straight or inverted to not more than one line. $I$ have alluded to this phenomenon at page 118 of $\mathrm{my}$ work on Squinting. When speaking of the loss of balance of power between two antagonistic muscles, I observed: "One, then, of two results must ensue ; either the more powerful muscle will draw the eye somewhat towards it; or its weaker antagonist will counteract this by increasing its tension, and this cannot be effected without causing some inversion of the opposite eye." The porition in which this patient maintained her head was also remarkable; it was bent forwards and downwards and to the right side, and rotated on its axis to the left; the object being evidently the avoidance of diplopia. The following phenomena were observed in connexion with this symptom.

1. It (the diplopia) was homonymous and laterad, the left-hand image being generally lower than the right, but parallel to it. Under no circumstances did the patient observe the images otherwise than parallel.

2. It extended to the extreme limit of both lateral fields ; the images being nearest together when the object was held directly in front of the patient, and furthest apart when to her extreme left. On moving the object into the left field, though the images receded from each other, they became level.

The treatment consisted, in the first instance, of ten grains of Dover's powder every night, and the following mixture three times a day.

Bo Vini colchici mxx; magnes. sulph. zij ; misturæ camphorm $\xi \mathbf{i}$. M.

This was continued till the $28 \mathrm{th}$, when the sensibility of the skin was less, but the paralysis remained unchanged. The bowels had been freely acted on, and tho patient complained of nausea and weakness. She was ordered to take two grains of disulphate of quinine twice daily, and an aloes and myrrh pill every alternate night.

On September $4 \mathrm{th}$, there being no alteration in the symptoms, a blister of the size of a shilling was applied over the eyebrow, which relieved the frontal pain; but, on the 11th, the eyeball remained very tender on pressure, especially on its upper and inner part, the outer being free from pain. Diplopia was still nearly as extensive to her right as to her left side. She was ordered to take three grains of iodide of potassium in camphor mixture three times a day.

September 28th. No improvement having taken place, the interrupted electro-magnetic current to the forehead and side of the nose was commenced on the 18th, and continued twice a week to the present time, but hitherto without results. The iodide of potassium was omitted; and the patient was ordered four grains of cinchonine with five minims of dilute sulphuric acid in water three times daily.

October 30th. The patient had continued taking the tonic mixtuie, and had been galvanised twice a week for one minute each sitting, with marked benefit; so that the cornea could now be everted to within one line of the outer canthus, and the pain and tenderness of the forehead and eyeball had en. tirely left her. The diplopia, however, still extended into the right half of her field of vision, so that she could not yet go about with the paralysed eye uncovered. The double images of an object ten feet in front of the patient, which on the 28th ult. could not be brought nearer together than five inches by a prism of $24^{\circ}$, could now be united by one of $20^{\circ}$. On testing the diplopia in the upper and lower fields, the left-hand image was lower when the object was held below the level of her face, but higher when it was held above. On moving it directly in front of the patient, at a distance of two feet, the images coalesced; also when held to the right and one line above the level of her face.

November 9 th. There was decided improvement in the position of the eyes and of the head, and the left cornea could be everted quite to the outer canthus. The lateral diplopia had disappeared from in the right half of the field of rision, and also from the ov front, and was now limited to the left half. She $\omega$ could go about with both eyes uncovered.

November 20th. Notwithstanding the patient could evert her left cornea to a normal extent, it required such a strong effort, that inordinate inversion of the right eye resulted; and hence diplopia still arose whenever she looked to her left. There was also diplopia in the lower half of her visual field. She complained of the mixture disagreeing with her, and of a slight return of the frontal pain. The galvanism, which had been discontinued the last fortnight, was resumed, and the mixture ordered in diminished doses.

December 21st. After two applications of the galvanism, the frontal pain disappeared, and did not return; and the patient was, to all appearance and in her own opinion, well. The only direction in which diplopia could be evoked was in the extreme outward and downward direction to the left, which, on shading each eye alternately, was seen to be due to the optic axis of the left eye not meeting that of the other on the object; for, the right being covered while both were apparently directed to it, the left made a slight movement downwards and outwards.

It is often difficult, sornetimes impossible, to trace a disease to its source- to say what is the first point of departure from health, or how this has been brought about; and this remark applies equally to the so-called predisposing, exciting, and immediate causes of disease. The case just narrated is an in. stance in point. There was no history of previous ill health; no exposure to cold or wet; no draught of cold air on a limited surface of skin or mucous mem brane; yet suddenly, and without warning of any kind (unless we regard as such the preceding conjunctivitis), the patient became affected with hyperesthesia of the ophthalmic division of the fifth nerve, complete paralysis of the sixth, and a partial paralysis of the fourth, or of one or two twigs of the third. What was the immediate cause of these symptoms?-what the materies morbi which could bring about such results? One can give but conjectural replies to these questions. It would be easy to cut the Gordian knot by saying that rheumatism was the disease-a name under which have been included many different affections, which agree only in the fact of their being painful. But if by rheumatism be meant a specific inflammation, affecting chiefly the fibrous and synovial structures, yet characterised as are other acute inflammations, not only by pain, but by redness, heat, and swelling, then the absence of these symptoms in the present case disentitles it to that appellation. The tenderness of the eyeball, which some might regard as evidence of rheumatic inflammation, was unaccompanied, as just observed, by any physical signs of inflammation. All the usual 
symptoms of sclerotitis (rheumatic ophthalmia) were absent; and, in their absence from the sclerotic, we have no right to assume their presence in the fibrous nerve-sheaths. How, then, is the tenderness of the eyeball to be accounted for, if inflammation be excluded? Probably we have a more satisfactory solution of this question on the hypothesis of neuralgia, however indefinite may be our knowledge of the real pathology of neuralgic affections. The site of this tenderness, it will be recollected, was not general, but chiefly over those ciliary branches of the lenticular ganglion which are derived from the fifth nerve. So, again, the hemicrania was concentrated in the cutaneous branches of the first division of the fifth. Whether this neuralgia of the fifth nerve stood in any causal relation to the paralysis of the sixth; in other words, whether this case is an example of the so-called reflex paralysis, or whether the hypermsthesia of the one nerve and the paralysis of the other were not both produced by a common canse acting within the orbit-we have no means of deciding.

As regards treatment, in the absence of a procise knowledge of the cause of the paralysis, it could not be otherwise than tentative, and to a certain extent empirical. Acting, in the first instance, on the supposition of the rheumatic character of the disease, colchicum and Dover's powder were prescribed; bat, the symptoms not yielding to these remedies, quinine was given, with as little apparent benefit; and, subsequently, iodide of potassium and bark. On the 18 th of September, or between five and six weeks from the commencement of the attack, the interrupted electro-magnetic current was commenced, and continued twice a week, for about one minute a sitting, till the first week in November, when the patient was so far recovered that it was discontinued. Can we attribute the favourable result to this particular remedy? So far as the evidence furnished by this case only goes, certainly not. It is true, the paralysis gradually disappeared; but this is the natural tendency of, I should say, the majority of these cases of paralytic strabismus. Then, as respects the pain, the only note from which we might infer benefit from galvanism was that of December 21st; while it must not be forgotten that, at an earlier period of the disease, the pain had undergone an increase during the same treatment, and then subsided, apparently altogether independent of the means employed. Comparing its effects on the nearalgia with those of the blister, it must certainly yield in efficacy to the latter.

It is not intended by these remarks to disparage galvanism as a valuable agent in the treatment of this class of diseases, but only to draw such inferences from the present case as we were warranted in doing by the phenomena.

\section{[To be continued.]}

EASY PoIsoning. A labourer was last week charged with attempting to kill himself by taking oxalic acid. He bought a bottle at a rag-shop, then went to a chemist's and bought two pennyworth of the poison, mixed it with water at a street pump, and drank it. The poison was sold by a lad under seventeen years of age in the employ of a chemist named Blackwell, who said he made no inquiry as to the purpose for which it was wanted. Oxalic acid was kept ready for sale by. his master in penny packets for the use of shoemakers, and was labelled "shoemakers' poison." He supplied the prisoner with two of these packets. Mr. Ellison severely censured the careless way in which the poison was sold, and remanded the prisoner.

\section{Cransactions of 迶ramcthes.}

\section{BATH AND BRISTOL BRANCH.}

CASE OF PUERPERAL CARDIAC EMBOHSM.

By Charles Steele, M.R.C.S., L.R.C.P., Clifton.

\author{
[Read March 1, 1866.]
}

WHEN a person in apparently good health, and following his or her usual vocation, suddenly expires, the consternation produced in the public mind bears only on the individual to whom this awful event has happened. But when death unexpectədly seizes upon a lying-in patient, in addition to its being deeply painful to all concerned, and becoming a topic of, conversation through the neighbourhood, it is so apt to give rise to insinuations as to the skill and discernment of the practitioner in attendance, that any case in which visible intelligible proof of the cause of death can be discovered, is of great value generally as well as directly. Of such a nature I hope to demonstrate the following to have been.

In the morning of Saturday the 26th of A ugust last, Mrs. W., without any previous exertion, or any pain, suddenly parted per vaginam with a large quantity of blood, while standing in her kitehen. As the hæmorrhage soon ceased, she paid no attention to it; but in the erening the same thing recurred. Her husband directly fetched me to her. I found her in bed with the hæmorrhagic pulse, but the flooding greatly abated. The chamber-utensil was almost, if not quite, half full of recent blood, undergoing coagulation. The attendants considered that the quantity voided in the morning exceeded this. No pain had been experienced. The os uteri was felt high up, soft, but not sufficiently open to admit the tip of a finger.

Under treatment, in the supine position, the patient passed no more blood till next midday, when pains commenced, accompanied by less copious discharge of blood. The as uteri was dilating, and soon I could introduce my finger sufficiently to make ont complete placental presentation. I presently administered chloroform; and, insinuating my hand between the placenta and nterus, seized the infant's feet, turned and brought away the child, followed immediately by the placenta. But little homorrhage occurred at the time and no unusual quantity afterwards. The child, a seven months' footus, was dead. The mother was put on nourishing diet, and did well for a few days.

On the Thursday following her confinement, which took place on a Sunday, the patient was seized with a severe shudder; after which she became rather dry and heated in her skin, thirsty, lost her appetite, and complained of pain in the sacral region. There was no pain or tenderness in the uterus. The lochia were diminished. The next day she had two violent shudders; the lochia stopped, and her head became hot and ached much.

In reply to the relations' anxious inquiries, I stated that some evil was certainly impending, which, though it might possibly prove slight, I feared would be serious, though its exact nature I could not predict.

The next morning she experienced another shudder ; and her head was so hot, with the temporal arteries throbbing, and eyes blood-shot with wild expression, and inclining upwards, that I ordered leeches to the temples, and a dose of calomel. By these means, the severe head symptoms wereabated. The friends wished a consultation, to which I willingly agreed, and in the 